\title{
Armado com sua fé e sua medicina: visões da África e do africano a partir do diário de Albert Schweitzer
}

\author{
Armed with his faith and his medicine: visions of Africa and the \\ African from Albert Schweitzer's diary
}

Naiara Krachenski Stadler

Resumo: Este artigo tem como objetivo compreender de que formas o discurso médico foi um elemento estruturante na produção e reprodução sobre estereótipos da África e do africano no contexto do imperialismo europeu. Para tanto, utilizamo-nos como fonte principal as memórias do médico alemão Albert Schweitzer sobre seu trabalho entre os anos de 1913 e 1916 na África Equatorial Francesa. Em um primeiro momento, analisamos os motivos e intenções apresentados pelo autor para iniciar sua jornada. Em um segundo momento, apontamos para dois estereótipos que são utilizados recorrentemente no texto de Schweitzer - a preguiça inata do negro e sua dependência ao álcool. Finalmente, apontamos outras duas características que aparecem nas memórias do médico e estruturam o modo de pensar imperialista: a pretensa superioridade europeia em relação aos africanos e a construção de uma alteridade animalesca.

Palavras-chave: Imperialismo; Discurso médico; Colônias africanas.

\begin{abstract}
The objective of this article is to comprehend in which ways the medical discourse was a structural element in the production and reproduction of stereotypes about Africa and the African in the context of European imperialism. Therefore, we use as main source the memoirs of the German physician Albert Schweitzer about his work between 1913 and 1916 in French Equatorial Africa. At first, we analyse the motives and intentions presented by

\footnotetext{
* Doutoranda no Programa de Pós Graduação em História na Universidade Federal do Paraná, Curitiba/PR, Brasil. E-mail: nkrachenski@gmail.com
}

(c) EY Direito autoral e licença de uso: Este artigo está licenciado sob uma Licença Creative Commons. Com essa licença você pode compartilhar, adaptar, para qualquer fim, desde que atribua a autoria da obra, forneça um link para a licença, e indicar se foram feitas alterações. 
the author to initiate his journey. Secondly, we indicate two stereotypes that were frequently used in Schweitzer's text - the innate laziness of the Black man and their addiction to alcohol. Finally, we point to other two characteristics in the physician's memoirs that structure the imperialist way of thinking: the so called superiority of the European and the construction of an animalistic Otherness.

Keywords: Imperialism; Medical discourse; African colonies.

\section{Introdução}

Este pequeno texto nasceu a partir de reflexões muito amplas e, em um primeiro momento, ainda um pouco desconexas suscitadas com a leitura de Orientalismo de Edward Said. O que me chamou a atenção nos escritos de Said neste momento específico foi sua ênfase na busca de uma experiência histórica distinta daquela a que estamos acostumados. Said nos questiona o porquê de ainda não termos conseguido admitir que as ações do imperialismo alteraram permanentemente nossa consciência do tempo e de sua construção epistemológica. ${ }^{1}$

No caminho aberto por Said encontram-se hoje pesquisadores interessados em continuar promovendo uma descolonização do conhecimento por meio de estudos que tragam à tona novos objetos de pesquisa e novas abordagens metodológicas. ${ }^{2}$ É o caso deste artigo, no qual pretendo analisar de que formas o discurso médico foi um participante ativo no processo de construção de estereótipos sobre a África e o africano no início do século XX a partir da experiência de trabalho de um médico alemão em uma colônia francesa.

\section{Albert Schweitzer, a medicina e a tarefa humanitária na África}

Apesar de a obra aqui analisada ser um compêndio dos escritos de Albert Schweitzer sobre sua experiência como médico na África Equatorial Francesa entre os anos de 1913 e 1916, ele não se dedicou à medicina até completar trinta anos de idade. ${ }^{3}$ Nascido em Kayserberg em 1875, então na província da Alsácia-Lorena pertencente à Alemanha, Schweitzer doutorou-se em Teologia e passou a lecionar na Universidade de Estrasburgo a partir de 1901. Mesmo tendo investido em diferentes áreas de atuação, o exercício da Teologia sempre foi presente nas suas obras e atividades, tendo publicado em 1906 o livro $A$ questão do Jesus histórico e, em 1931, O misticismo de Paulo, o Apóstolo. Lado a lado com sua carreira de docente, Schweitzer era conhecido pelos seus dotes musicais, em especial, como organista e pelas suas interpretações das obras de Johann Sebastian Bach. Em 1905, no entanto, já com duas carreiras 
praticamente estabilizadas, Schweitzer propôs-se a trabalhar junto com a Sociedade Missionária Francesa e deu início aos estudos de Medicina.

Interessa-me pontuar aqui, de forma mais ou menos detida, a razão apresentada por Schweitzer para ter largado sua carreira de docente e de músico para atuar como médico em Lambaréné, região do rio Ogooué, na então colônia francesa do Gabão.

O próprio Schweitzer menciona repetidas vezes em seus escritos o senso de missão humanitária que o motivou a trabalhar com os povos colonizados. A partir de leituras de testemunhos de missionários e de um forte dever cristão para com o outro, Schweitzer incomodava-se com o fato de que os europeus se preocupassem tão pouco "com a grande tarefa humanitária" que se apresentava a eles em África. Ao dar-se conta do pequeno número de médicos que se dispunha a ir para aquelas longínquas regiões do globo, Schweitzer afirma contundentemente que "compete à nossa sociedade o dever de tomar para si tal tarefa. (...) Só então começaremos a reconhecer e a cumprir a responsabilidade que cabe a nós, homens civilizados, perante os nativos daquela região". ${ }^{4}$ Não é necessário ir longe para reconhecer aqui os ecos do tão conhecido poema de Rudyard Kipling: "Tomai o Fardo do Homem Branco/ As guerras selvagens pela paz/ Enchei a boca dos famintos,/ e proclamai o cessar das doenças". A noção de missão civilizatória era forte e recorrente não só na literatura ${ }^{5}$, nos periódicos ${ }^{6}$ e na cultura visual ${ }^{7}$, mas esteve presente também no campo científico. Dentre as disciplinas que mais se desenvolveram e ganharam destaque, ao mesmo tempo em que justificaram o colonialismo, estão a antropologia, a geografia e a medicina.

O discurso médico nas colônias teve um papel fundamental na construção do "africano" como um objeto de conhecimento. ${ }^{8}$ A partir das descrições dos comportamentos e costumes dos nativos e das doenças que se proliferavam nas selvas africanas, a ciência médica forjou a identidade do nativo africano tendo como bases o racionalismo e o empirismo da profissão, além de elaborar um sistema de classificação e de práticas úteis à manutenção do sistema colonial. De forma geral, o discurso médico nas colônias, baseados na Medicina Tropical, forjou uma alteridade africana que era, em todas as suas manifestações, diferente da identidade do homem europeu. Segundo Jefferson Olivatto da Silva,

Manifestações corporais e estados psicológicos desconhecidos não correspondiam aos diagnósticos clínicos ocidentais, corroborando o etnocentrismo sobre a alteridade africana, que pelo discurso biomédico, tornoulhe uma natureza doentia. ${ }^{9}$

Nos relatos de Schweitzer, a prescrição médica é utilizada, muitas vezes, como justificativa à segregação de brancos e de negros. Ao descrever 
a maior suscetibilidade dos nativos às doenças infecciosas, Schweitzer pôde constatar que os conselhos que os missionários lhe haviam dado no navio que ia para as colônias eram verdadeiros: "Os missionários avisaram-me desde o começo que na África é preciso evitar sempre que possível que os negros entrem nas habitações dos brancos. Trata-se de uma medida de sobrevivência pessoal". ${ }^{10}$

"Medida de sobrevivência pessoal": a medicina tropical também foi responsável por inúmeros excessos e desmesuras cometidas nos territórios coloniais. De acordo com Sílvio Correa, o caráter experimental do discurso médico nas colônias

foi responsável por uma série de abusos feitos sob chancela de autoridades médicas, civis ou militares. Uso de cobaias humanas para experimentar vacinas contra várias doenças tropicais e isolamento forçado dos doentes foram algumas medidas empregadas pela medicina experimental durante o colonialismo. ${ }^{11}$

Contudo, apesar dos problemas enfrentados pelo homem branco em terras africanas, encontramos na narrativa de Schweitzer uma íntima relação entre o exercício da medicina e o senso de missão civilizatória que acometia os europeus. Os problemas da precariedade das instalações, da falta de medicamentos, da demora em consegui-los e das dificuldades em explicar aos nativos como se devem utilizar tais remédios são entendidos por ele como "contrariedades passageiras" em face à "alegria de poder agir e realizar um socorro tão necessário". ${ }^{12}$ Não é de surpreender, pois, a quantidade de elogios destinados à medicina ocidental pela sua excelência em produzir remédios tão maravilhosos que mesmo com parcos recursos, um só médico poderia empreender grandes benefícios aos nativos. ${ }^{13}$

A missão de civilização levada a cabo pelos europeus tinha como pano de fundo não só o progresso cultural e tecnológico, mas também a esfera religiosa, especificamente, a missão de levar a palavra da Cristandade. Essa aliança entre homem civilizado e cristão é marca recorrente na narrativa de Schweitzer que afirmava desde o início de sua missão sua responsabilidade teológica. Ao relembrar as cirurgias que fazia nos nativos, Schweitzer lembra também dos momentos pós-cirúrgicos quando falava com o nativo doente e com os demais ali presentes sobre a vida e a obra de Jesus Cristo, sobre como Ele havia ordenado ao médico e à sua esposa que viessem ao Ogooué e também de seus amigos brancos que haviam ficado na Europa e lhe mandavam suprimentos para a continuidade de sua missão em África. ${ }^{14}$ Em outras palavras, Schweitzer utilizava-se da sua autoridade como médico para falar aos nativos a respeito de como a civilização do homem branco juntamente com a religião cristã representava para os negros um meio à salvação. 
Contudo, não se pode dizer que Schweitzer não estivesse minimamente consciente dos problemas que a presença europeia causou na África. Ainda que em nenhum momento de suas memórias o autor deixe explícito o reconhecimento da violência sofrida pelos nativos no processo de colonização e na sua manutenção, ele afirma que os negros sofriam muito mais das doenças que os brancos trouxeram à África: "Só aqui pude perceber que a maior parte do trabalho do médico nos trópicos é lutar contra doenças medonhas e horrendas que os europeus trouxeram para essa gente primitiva". ${ }^{15}$ Daí decorre que Schweitzer acredite que a "missão de bem" do homem branco na África não é uma missão de caridade, mas uma missão de reparação, uma vez que o sofrimento africano decorre, em maior medida, dos atos dos europeus. ${ }^{16} \mathrm{Tal}$ reparação, no entanto, é entendida apenas como minimizar as dores físicas dos nativos a partir da técnica médica ocidental. Ela não prevê, em nenhum momento, o fim da colonização nem tampouco a emancipação dos nativos.

\section{A África e o africano: os usos de estereótipos}

Conforme afirmei de anteriormente, o discurso imperialista sobre a África e sobre os africanos se construiu a partir dos usos e da constante repetição de estereótipos. Como elementos estruturantes da ideia imperial e do aparato colonial os estereótipos funcionavam a partir da lógica de diferenciação entre o "eu" narcísico do colonizador - não só o indivíduo, mas toda a coletividade a que este indivíduo pertencia - e o "outro" colonizado. Um senso de diferenciação construído artificialmente, em um primeiro momento, se tornou bastante real para aqueles que incorporaram nos seus pensamentos e nas suas atitudes um posicionamento de segregação e de superioridade. Nessa lógica de construção de mundo, os estereótipos assumem um papel de regulação dessa separação entre o "eu" e o "outro" e agem como mecanismos para preservar a ilusão do controle que se tem sobre o self e sobre o mundo que o cerca. ${ }^{17}$

Desde o início de sua narrativa, Schweitzer comenta sobre o que ouvia dizer acerca do problema da mão-de-obra nativa, não só na Europa pelos relatos de missionários e ex-agentes coloniais, mas também logo da sua chegada em Ogooué quando o responsável pelo posto missionário em que se instalara lhe aconselhara: "sua aprendizagem africana está apenas começando (...) terá de aceitar dia após dia como uma contingência perpétua: a falta de boa-fé dos nativos". ${ }^{18}$ Poucos meses após sua chegada, contudo, o próprio Schweitzer constatava a "má vontade" e a "preguiça assombrosa" de nativos que haviam lhe sido recomendados para auxiliar na construção de um posto de atendimento. Neste episódio, em particular, Schweitzer reitera que a construção só pôde ser encaminhada satisfatoriamente porque ele próprio serviu de exemplo para os operários nativos: "Eu próprio empunhei uma picareta, dando o exemplo, enquanto o feitor negro da turma, deitado à sombra duma árvore, se dignava dirigir-nos de vez em quando algumas palavras de encorajamento". ${ }^{19}$ 
Não bastando o fato de o negro ter preguiça e má vontade de trabalhar, ele ainda trabalharia mal. Segundo os relatos de Schweitzer, ele precisava de três empregados domésticos para darem conta do serviço de sua pequena casa, serviços estes que, segundo ele, poderiam ser feitos por uma só criada europeia. ${ }^{20}$ Tal situação se fazia pior, uma vez que, conforme seguiam os discursos preconceituosos e conforme nos narra o próprio Schweitzer, os negros precisavam de constante vigilância para trabalharem honestamente, visto a recorrência dos furtos pelos nativos. Pelo que nos apresenta Schweitzer, essa situação de desonestidade não é tão somente um desvio moral por parte dos nativos, que poderia ser corrigida com uma educação religiosa, por exemplo, mas uma deficiência de sua própria natureza na medida em que ele afirma que os próprios nativos pedem para os brancos que os mantenham sob olhar atento senão "o que não estiver debaixo de chave 'se evapora"'. ${ }^{21}$

É necessário aqui fazer uma pequena pausa na narrativa de Schweitzer. Quando ele diz que os nativos os "obrigam a observar essas medidas de cautela para que não venham a ser responsabilizados pelos eventuais furtos ou desaparecimentos", ele está assumindo que os próprios nativos compreendem sua "natureza amoral" propícia ao roubo e ao engano quando, na realidade, este "pedido de vigilância" poderia ser visto como uma forma que os nativos encontraram de diminuir as acusações contra eles, ou seja, vivendo em uma realidade onde se é constantemente colocado à prova, onde cotidianamente sofrem humilhações sendo acusados de coisas que não fizeram, muitos nativos assumiriam a postura de só trabalhar sob olhar do homem branco para que tais acusações não tenham margem de serem feitas. Entende-se aqui a mesma situação de forma brutalmente diferenciada: ao invés de assumir a natureza má do homem negro, vê-se nesse posicionamento um ato de resistência diária encontrado pelos nativos.

Esta postura já bastante difundida e reiterada na narrativa de Schweitzer de que o negro é preguiçoso e precisa de supervisão constante legitimava cada vez mais o controle e o poder do colonizador sobre o sujeito colonizado. Conforme afirmou Silvio Correa:

Predominava a ideia na Europa, mesmo em círculos abolicionistas, de que os negros precisariam da supervisão rigorosa de um estado civilizado antes que pudessem embarcar no "curso natural" da racionalidade do mercado. Isso legitimou ainda mais o colonialismo. Nota-se que o colonizador branco é quem parecia ser o protagonista do progresso e não o trabalhador africano. Era como se o seu olhar tivesse um poder demiurgo que fazia o trabalho alheio tornar-se produtivo. Porém, mais do que seu olhar, era sua violência que movia os trabalhadores. ${ }^{22}$ 
Se a ideia de que o negro era preguiçoso legitimava a violência e a subjugação ao trabalho compulsório, ela também nos sinaliza uma característica em nenhum momento pontuada por Schweitzer: a fragilidade do projeto colonialista. De acordo com Frederik Cooper, o sistema colonial era constantemente colocado à prova, testado, limitado e remodelado no cotidiano das relações interpessoais existentes na realidade da colônia. ${ }^{23}$ Segundo este autor, "o Império capitalista, na Índia assim como na África, não foi tão consistentemente capitalista quanto se pensa; o domínio burocrático não tão consistentemente burocrático; a fabricação dos sujeitos coloniais não definia exatamente que tipo de sujeitos deveriam ser produzidos". ${ }^{24}$ A ideia de que o negro africano era preguiçoso se construiu a partir do não-enquadramento dos nativos nos modelos de trabalho impostos pelos europeus, um regime de trabalho, ele mesmo, escravo.

No entanto, ainda que Schweitzer acredite que o negro deva ser constantemente controlado ele refuta a ideia de que a mão-de-obra nativa é ruim porque o negro é preguiçoso. Segundo ele, o nativo é, em geral, um bom trabalhador; o problema é que ele é um "trabalhador ocasional". De acordo com a explicação elaborada por Schweitzer, o nativo, por ser um "filho da natureza", trabalha para suprir as necessidades que a natureza não supre, como pagar por uma esposa, comprar roupas e acessórios, consumir álcool e tabaco etc. Sendo o nativo um "homem livre", os brancos reclamam porque "não os têm à sua mercê porque os nativos não estão reduzidos à necessidade de um ganho regular, já que desconhecem a luta pela existência". ${ }^{25}$ Conforme notou o próprio Schweitzer e conforme sabemos, os colonizadores tentaram impor aos nativos o modelo racional de trabalho a partir de duas forças: a cobrança de tributos e a criação de necessidades a partir do consumo de mercadorias supérfluas. ${ }^{26}$ Contudo, Schweitzer constata, não sem uma certa tristeza, como um bom protestante, de que este modelo imposto só fez criar "um homem ávido de dinheiro para prazeres, e não um trabalhador consciencioso e sensato" 27 , que entenda o valor do trabalho como elemento estruturante da civilização e para a elevação do espírito.

Outra característica do homem africano apontada na escrita de Schweitzer é a sua dependência à aguardente. Conforme Schweitzer constatou no episódio da construção do posto de atendimento, os nativos preferiam o pagamento de seu trabalho em cachaça, pois, segundo eles, o homem branco a comprava por um preço inferior. Este problema com o álcool é constante nas observações do médico que vê em tal dependência um problema não só social e de saúde do nativo, mas também da própria saúde do projeto de civilização. Logo que chega a Lambaréné, Schweitzer escuta de um comerciante branco que aquela região era muito mais próspera há vinte anos. Ao perguntar o porquê não é mais, o comerciante lhe responde: "por causa da cachaça..." ${ }^{28} \mathrm{O}$ mesmo homem continua a conversa afirmando que o álcool não é só um problema 
da região do Ogooué, mas está disseminado por várias colônias e por todos os povos nativos: "por toda parte o álcool é o adversário de todo e qualquer trabalho civilizador". ${ }^{29}$

Schweitzer bem sabe que o álcool é um real problema para o desenvolvimento das regiões africanas e afirma que "funcionários, negociantes, missionários e chefes africanos são unânimes em declarar que a importação do álcool devia ser interditada". Porém, a aguardente era um excelente artigo aduaneiro e representava grandes somas nas receitas da colônia, de tal forma que impedir sua entrada era uma atitude impensável pelos gestores das finanças coloniais. Dessa maneira, Schweitzer mais explicita o problema e pensa em gerenciá-lo da melhor maneira possível, do que busca alguma alternativa para resolver tal impasse. No entanto, ainda que ele identifique que este problema surgiu entre os africanos a partir do contato com os povos europeus e da importação da cachaça, ele não desmente que os africanos tenham uma propulsão muito maior ao descontrole causado pela bebida do que, por exemplos, os brancos. Podemos identificar aqui mais um argumento - mesmo que de forma indireta - sobre a natureza amoral dos nativos, com a falta do controle racional sobre os impulsos dos desejos.

$$
* * *
$$

Todo o cerne das relações que os europeus procuraram estabelecer com os nativos africanos tinha como base a ideia da inferioridade do homem negro em relação ao homem branco. O médico Albert Schweitzer, ganhador do Prêmio Nobel da Paz em 1952, inclusive, não escapava a essa lógica de mundo.

Em um momento no qual Schweitzer se propõe a pensar sobre os problemas sociais da selva ele se questiona como deveriam ser as relações entre o branco e o negro e se os homens brancos deveriam tratá-los como iguais ou inferiores. Schweitzer afirma que os homens brancos deveriam mostrar aos negros o respeito que é devido a todos os seres humanos. No entanto, tal "espírito de fraternidade" não deve ocultar a "autoridade natural" que o branco exerce sobre o negro:

O negro é como uma criança. Sem autoridade não se obtém nada de uma criança. Por consequência, preciso estabelecer fórmulas entre nossas relações de maneira que a minha autoridade natural se manifeste. Defino da seguinte forma a minha atitude para com o primitivo: sou teu irmão, mas teu irmão mais velho. ${ }^{30}$

O escritor nigeriano Chinua Achebe, ao discorrer sobre o racismo na obra de Joseph Conrad, comenta ironicamente sobre esta ideia de que o negro seria como um irmão mais novo do branco: 
Em um comentário que tem sido frequentemente citado Schweitzer diz: "o africano é meu irmão, mais meu irmão mais jovem". E assim ele passou a construir um hospital apropriado às necessidades dos irmãos mais jovens, com padrões de higiene da prática médica dos dias que antecederam o surgimento da teoria dos germes. Naturalmente ele se tornou uma sensação na Europa e na América. Os peregrinos se reuniam, e acredito que ainda se reúnem mesmo ele tendo passado adiante, para testemunhar o milagre prodigioso em Lambaréné, na orla da floresta primitiva $^{31}$

Achebe utiliza-se aqui de ironia para tratar da questão dos benefícios que o homem branco teria levado à África, identificando nessa postura de benfeitoria uma atitude racista e que diminui a dignidade do homem negro. Também Frantz Fanon comenta sobre o ataque ao respeito ao negro que as atitudes de bondade escondem: quando brancos dirigem-se aos negros, eles os tratam como crianças - uso de mímicas, sussurros, gentilezas e amabilidades -, "pode-se argumentar que não há intenção nem desejo de afligi-lo. Concordamos; mas é justamente essa ausência de intenção, esta desenvoltura, esta descontração, esta facilidade em enquadrá-lo, em aprisioná-lo, em primitivizá-lo, que é humilhante". ${ }^{32}$

Para Schweitzer, inclusive, esta "decadência biológica e moral" dos nativos representa um perigo para a própria moral e civilidade que os homens brancos possuem. ${ }^{33}$ Segundo ele, o homem branco deve cultivar sua erudição em meio à selva e ao esgotamento que a interação com os nativos lhe impõe; é só a partir do cultivo da intelectualidade da cultura ocidental (no seu caso, continuar tocando as obras de Bach no piano ou fazendo leituras de obras clássicas) que o homem branco pode manter sua moralidade intacta e continuar com seu dever de civilizador. Aquele que consegue assim recolher-se e retomar suas forças, "torna a sentir-se um ser humano. (...) Cedo ou tarde [aquele que não o fizer] será corroído pelo medonho prosaísmo da vida africana". ${ }^{34} \mathrm{E}$ é justamente por causa deste contato diário com os nativos que Schweitzer tenta explicar o porquê de muitos brancos abandonarem seu senso de missão civilizatória: "Acredito piamente que os homens que falam hoje sem caridade dos nativos chegaram à África cheios de idealismo; mas os conflitos cotidianos os esgotaram e desencorajaram, pouco a pouco". ${ }^{35}$

Uma outra imagem bastante recorrente à época do imperialismo era a de que o homem negro seria como que o "elo perdido" entre o homem e o macaco, ou seja, entre o homem completamente evoluído - branco - e a origem da espécie humana, o macaco, ideia que era cada vez mais aceita e difundida entre a comunidade cientifica e a opinião pública do evolucionismo. Dessa forma, a África era entendida como um lugar primitivo e fora do tempo, onde a evolução não ocorreu sob nenhum aspecto - nem biológico, nem cultural. 
Tomando emprestado um termo de Silvio Correa, a África era vista a partir da lógica da "alteridade animalesca", onde não só seu território era coberto por uma natureza selvagem indomável, mas também seus habitantes seriam muito próximos aos animais. ${ }^{36}$

Esta ideia foi fortemente utilizada pela cultura visual da época, onde em qualquer imagem que aparecesse o negro utilizavam-se recursos imagéticos que lembravam sobremaneira o desenho de animais exóticos, principalmente o macaco. Representados com barrigas salientes, bocas exageradamente grandes e atitudes "irracionais", a cultura visual deu conta de criar um imaginário do homem negro que o associa de pronto ao primata. Ao lado disso, claro, tem-se o crescimento dos estudos de primatologia e genética que fortaleceram cada vez mais a ideia de que o nativo africano seria ainda o homem primitivo.

Estas ideias aparecem de forma indireta e de maneiras bastante sutis na narrativa de Schweitzer. Mesmo sendo um "homem de saber", ele não afirma em nenhum momento desta obra que acredite na teoria da evolução nem tampouco que os nativos seriam este elo perdido. No entanto, as imagens que ele possuía da África anteriormente à sua chegada, ao invés de se alterarem com sua experiência no local, se confirmaram de vez:

Água e selva...! Quem consegue reproduzir essas
impressões? Para nós tudo parece sonho. Aqui as paisagens
antediluvianas, que vimos ao acaso em desenhos fantásticos,
se tornam realidade. (...) Aqui é impossível enganar-se:
suspensas numa palmeira e se mexendo, duas caudas de
macacos. Agora seus dois proprietários estão visíveis.
Agora, estamos realmente na África! ${ }^{37}$

Ao estar diante de paisagens idílicas e de animais exóticos, opera-se na experiência de Schweitzer uma presentificação do estereótipo, ou seja, é só quando o médico consegue enxergar aquela imagem de que já dispunha que ele se vê realmente na África.

De forma ainda mais sutil e indireta, podemos entender o nativo como portador dessa alteridade animalesca sob a ótica de Schweitzer quando observamos a recorrente menção de que os africanos alimentam-se quase que exclusivamente de bananas. É verdade também que ele descreve em vários momentos a dificuldade de se conservar alimentos naquela região úmida e quente, mas, de qualquer maneira, se há algo que marca uma diferenciação entre os homens brancos e os nativos era que estes estavam sempre providos de sua dieta básica: a banana. Seja levando para viagens de trabalho, para expedições de busca ou mesmo para a espera na fila do atendimento médico, o negro sempre é descrito tendo esta fruta como alimento primordial. Digo que aqui a avaliação da alteridade animalesca se dá de forma indireta porque, ainda com tal recorrência sobre o assunto, Schweitzer não faz uma ligação 
direta entre o africano e o macaco como comedores de banana. No entanto, se pudéssemos avaliar seus hipotéticos leitores, que também traziam consigo um aporte imagético bastante sustentado na imagem negro-macaco, podemos inferir que tal recorrência de observação na narração de Schweitzer não passava despercebida pelos seus leitores de então, nem tampouco pelos seus leitores de agora.

A ideia da alteridade animalesca se relaciona, em última instância, àquela ideia de que o negro é preguiçoso, na medida em que ambos os estereótipos confirmam a regra de que o negro africano deve ser imediatamente enquadrado nos modelos da civilização europeia para o próprio bem do projeto colonial. $\mathrm{E}$ é justamente essa ideia de enquadrar o africano em uma lógica de mundo que não é sua que denuncia mais uma vez as limitações da ideia imperial.

Os estereótipos utilizados por Schweitzer na composição de sua narrativa não são novidade para aqueles que estudam o colonialismo europeu em África. No entanto, é justamente a reciclagem de argumentos já conhecidos que é importante pontuar aqui. Quando entendemos que o Império não era uma unidade política consistente, que as experiências coloniais se mostravam muito mais plurais do que aquilo que o discurso oficial queria, entendemos a necessidade que os europeus tinham de apresentar para eles mesmos discursos que corroborassem suas atitudes e justificassem o empreendimento colonial, ou seja, a recorrência dos estereótipos servia a uma constante manutenção ideológica do Império.

\section{Considerações finais}

Após percorrer a narrativa do médico Albert Schweitzer sobre seu trabalho na África Equatorial de forma mais ou menos detalhada, pude perceber a recorrência de tópicos estereotipados que atuaram (e, não nos enganemos, continuam atuando) na consolidação do racismo nas sociedades ocidentais.

Em primeiro lugar, observo a manutenção dos discursos já bem consolidados à época que retratam os nativos africanos e sujeitos coloniais como povos inferiores não só tecnicamente, mas cultural e moralmente. A recorrência e constante atualização dessas ideias, não só a partir de relatos de missionários e médicos que vivenciaram experiências em solo africano, mas também de uma cultura literária, visual e científica, foi central para a promoção de políticas coloniais que tomassem os sujeitos colonizados sob esta ótica e justificassem os processos de espoliação de direitos, violência e opressão.

As imagens de que o negro era inferior, moralmente debilitado, primitivo etc gestaram não só uma atmosfera cultural e social contrária à presença desses sujeitos em solo europeu ou mesmo americano (lembremos, inclusive, que tal atmosfera prenha de racismo e segregação não está somente no passado com as políticas nazistas ou as tentativas de impedir sujeitos das ex-colônias de pedir abrigo, mas encontram-se vivas ainda hoje nas políticas contra imigrantes 
levadas a cabo por boa parte da sociedade civil ocidental), mas também, e principalmente, criou práticas políticas que perpetraram vários tipos de violência contra tais povos que foram de todo o modo muito bem justificadas.

É justamente nesse ponto que gostaria de salientar mais uma vez os pensamentos de Said que me trouxeram a tal reflexão. A experiência do imperialismo foi, muitas vezes, deixada de lado ao se considerar a construção da mentalidade da cultura ocidental. No entanto, os discursos iniciados com esta experiência histórica concreta produziram ecos em todas as esferas da vida dos povos ditos civilizados e fazem parte do seu processo de entendimento e construção do mundo. Ou seja, analisar historicamente a construção de estereótipos sobre o Outro e avaliar o impacto desses discursos na produção de conhecimento é uma maneira possível de se entender a manutenção dos discursos de ódio, segregação e violência que perpassaram diferentes experiências no passado e continuam a constituir nossas vivências neste século XXI.

\section{Notas}

1 SAID, Edward. Orientalismo. São Paulo: Cia. das Letras, 2007, p. 18.

2 WENZEL, Jennifer. "Decolonization" In SZEMAN, I. \& BLACKER, S. \& SULLY, J. $A$ companion to critical and cultural theory. No prelo. Texto disponível em http://academia. edu.

3 SCHWEITZER, Albert. Entre a água e a selva: narrativas e reflexões de um médico nas selvas da África equatorial. São Paulo: Ed. UNESP, 2010.

4 Idem, p. 12.

5 Sobre literatura de aventura colonial ver BREPOHL DE MAGALHÃES, Marion. Imaginação Literária e Política: os alemães e o imperialismo (1880 - 1945). Uberlândia: EDUFU, 2010.

6 Sobre o papel da imprensa ver CORREA, Sílvio. "A 'africanização' da Europa pelas caricaturas da imprensa periódica ilustrada alemã". Texto apresentado no Colóquio "Civiliser le monde, ensauvager l'Europe", realizado na Universidade de Estrasburgo entre 22 e 23 de junho de 2015, gentilmente cedido pelo autor.

7 Sobre a cultura visual ver CIARLO, David. Advertising Empire: race and visual culture in Imperial Germany. Massachusetts: Harvard University Press, 2011.

8 VAUGHAN, Megan. Curing their ills: colonial power and African illnes. Standford: Standford University Press, 1991, p. 8.

9 OLIVATTO DA SILVA, Jefferson. "As resistências africanas diante das medidas preventivas coloniais contra a doença do sono na Zâmbia (1890-1920)" In História: Questões \& Debates, Curitiba, v. 62, n. 1, jan./jun. 2015, p. 76.

10 SCHWEITZER, op. cit., p. 39.

11 CORREA, Sílvio. "Evicção da fauna bravia: medida radical de saneamento na África colonial" In Revista de Ciências Humanas, Viçosa, v. 14, n. 2, jul-dez. 2014, p. 419. 
12 SCHWEITZER, op. cit., p. 45.

13 Idem, p. 46, 53.

14 Idem, p. 98.

15 Idem, p. 96.

16 Idem, p. 175.

17 VAUGHAN, op. cit., p. 2.

18 SCHWEITZER, op.cit., p. 38.

19 Idem, p. 52.

20 Idem, p. 69.

21 Idem, p. 70.

22 CORREA, Silvio. "As ambigüidades do trabalho na África Oriental Alemã" In I Seminário Internacional de História do Trabalho - V Jornada Nacional de História do Trabalho, Universidade Federal de Santa Catarina, Florianópolis, 25-28 de outubro de 2010, p. 5-6.

23 COOPER, Frederik. Colonialism in question: theory, knowledge, history. Berkley: University of California Press, 2005, p. 235.

24 Idem, p. 239-240 - tradução livre da autora.

25 SCHWEITZER, op.cit., p. 117-118.

26 CORREA, op. cit. p. 4.

27 SCHWEITZER, op.cit., p. 119.

28 Idem, p. 33.

29 Idem, p. 33.

30 Idem, p. 133.

31 ACHEBE, Chinua. "An Image of Africa: Racism in Conrad's 'Heart of Darkness" In Massachusetts Review. 18. 1977 - tradução livre da autora.

32 FANON, Frantz. Pele Negra, Máscaras Brancas. Salvador: EDUFBA, 2008, p. 45.

33 SCHWEITZER, op. cit., p. 136.

34 Idem, p. 152.

35 Idem, p. 137-138.

36 CORREA, Silvio. "A 'partilha do gorila' entre ciência e literatura de alhures e saberes locais" In História: Questões \& Debates, Curitiba, v. 62, n. 1, jan/jun. 2015, p. 119.

37 SCHWEITZER, op.cit., p. 31.

Recebido em 10/02/2017

Aprovado em 05/05/2018 